\title{
Problem Video Game Playing scale Portuguese Version
}

Helena ESPÍRITO-SANTO*, João TOMÁZIO, Ilda MASSANO-CARDOSO, Fernanda DANIEL

Miguel Torga Institute | Research \& Development Department | Coimbra | Portugal

Contact details: helenum@gmail.com

Introduction

\section{Background}

DSM-5 proposed Internet Gaming Disorder as a condition for future research (APA, 2014). Given the existence of one available assessment instrument - the Problem Video Game Playing scale (PVP) - it is relevant and timely to verify its psychometric properties in Portuguese adults.

\section{Objectives}

To reexamine the psychometric properties of PVP in Portuguese adult gamers.

\section{Methods}

$\star$ Sample \& Procedures. One hundred and eleven adult gamers completed an online evaluation comprising the PVP, and a questionnaire designed for the study.

$\star$ Problem Video Game Playing scale. The PVP was developed by Tejero Salguero \& Bersabé Morán (2002) to assess the addition to video games and was based on the DSM-IV criteria for substance dependence and for pathological gambling. PVP comprises 9 questions with a yes/ no format regarding the occurrence of video game playing behaviors during the previous year.

$\star$ Questionnaire designed for the study elicited information about number of different games played, presence (Yes/No) and frequency of other dependencies, namely substance abuse.

$\star$ Statistical Analyses. We used SPSS 20.0 for Macintosh. We performed a factor analysis using the principal components solution with Varimax rotation. We plotted the scree test of Catell to identify the number of factors to be extracted. We analyzed the PVP internal consistency, calculating the Cronbach's alpha coefficient. Construct validity was assessed through correlational analysis between PVP and number of games played, presence and frequency of substance abuse.

\section{Results}

$\star$ Data suitability for factor analysis. The Kaiser-Meyer-Olkin Measure of Sampling Adequacy (should be $\geq .6$; was of .730) and the Bartlett's Test of Sphericity value (should be $\leq .05$; was of <.001), allowing us to verify data suitability for factor analysis (Pallant, 2007).

$\star$ Principal components analysis and scree plot. A principal components analysis and the scree plot inspection revealed a meaningful one-factor solution (eigenvalue $>1$ ), explaining $33.6 \%$ of the total variance. The Component Matrix, presenting each item unrotated loading, showed that all items loaded quite strongly (>.4) serw thet

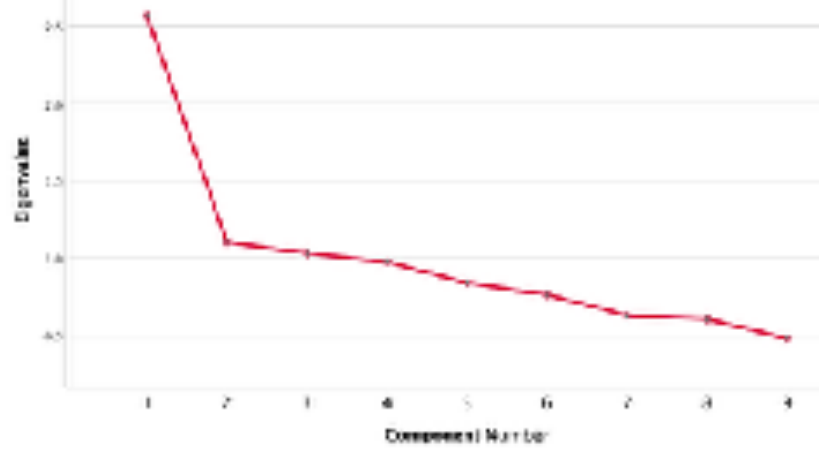

$\star$ Internal consistency. Removing two of the items, PVP reliability values were similar to previous studies (Cronbach's alpha $=.66$ ).

$\star$ Construct validity. Statistically significant associations between the PVP and other measures supported the construct validity.

\begin{tabular}{|lcccc|}
\hline & 1 & 2 & 3 & 4 \\
\hline 1. PVP & - & $.24^{* *}$ & $.19^{\star}$ & $.17^{\star}$ \\
2. Number Games & & - & .12 & .01 \\
3. Other abuse & & & - & $.57^{\star \star}$ \\
4. Frequency Abuse & & & & - \\
\hline${ }^{* *} p<.001 ;{ }^{*} p<.01$ & & & & \\
\hline
\end{tabular}

\section{Conclusions}

$\star$ Results confirm that problematic video gaming can be measured reliably and validly through the Portuguese version of PVP.

$\star$ It is proposed to test PVP using a wider national sample and to analyze it with clinical samples to determine a cutoff value.

\section{References}

American Psychiatric Association [APA]. (2014). DSM-5 - Manual de diagnóstico e estatística das perturbações mentais (5. ${ }^{a}$ ed.). Lisboa: Climepsi Editores

Pallant, J. (2007). SPSS Survival Manual: A step by step guide to data analysis using SPSS for Windows (3rd Ed.). Maidenhead: McGraw Hill Education.

Tejeiro Salguero, R. A. e Morán, R. M. B. (2002). Measuring problem video game playing in adolescents. Addiction, 97(12), 1601-1606. doi: 10.1046/j.1360-0443.2002.00218.x 